\title{
Targeted Acid-Sensing lon Channel Therapies for Migraine
}

\author{
Nazia Karsan ${ }^{1}$ (D) Eric B. Gonzales ${ }^{2} \cdot$ Gregory Dussor $^{3}$ \\ Published online: 16 March 2018 \\ (C) The Author(s) 2018
}

\begin{abstract}
Acid-sensing ion channels (ASICs) are a family of ion channels, consisting of four members; ASIC1 to 4 . These channels are sensitive to changes in $\mathrm{pH}$ and are expressed throughout the central and peripheral nervous systems - including brain, spinal cord, and sensory ganglia. They have been implicated in a number of neurological conditions such as stroke and cerebral ischemia, traumatic brain injury, and epilepsy, and more recently in migraine. Their expression within areas of interest in the brain in migraine, such as the hypothalamus and PAG, their demonstrated involvement in preclinical models of meningeal afferent signaling, and their role in cortical spreading depression (the electrophysiological correlate of migraine aura), has enhanced research interest into these channels as potential therapeutic targets in migraine. Migraine is a disorder with a paucity of both acute and preventive therapies available, in which at best $50 \%$ of patients respond to available medications, and these medications often have intolerable side effects. There is therefore a great need for therapeutic development for this disabling condition. This review will summarize the understanding of the structure and CNS expression of ASICs, the mechanisms for their potential role in nociception, recent work in migraine, and areas for future research and drug development.
\end{abstract}

Key Words Migraine $\cdot$ ASICs $\cdot$ Headache $\cdot$ Cortical spreading depression $\cdot$ Therapeutics $\cdot$ Ion channels

\section{Introduction to Migraine}

Migraine is a common and disabling headache condition affecting millions of people worldwide [1]. The World Health Organization (WHO) classifies migraine as the sixth most disabling disorder globally [1], with a total prevalence of 15 to $18 \%$, regardless of which country is surveyed [2]. Typically, migraine tends to affect people during their peak working years so there is significant disability and subsequent socioeconomic impact associated with the condition [3].

Electronic supplementary material The online version of this article (https://doi.org/10.1007/s13311-018-0619-2) contains supplementary material, which is available to authorized users.

Gregory Dussor

Gregory.dussor1@utdallas.edu

1 Headache Group, Department of Basic and Clinical Neuroscience, Institute of Psychiatry, Psychology and Neuroscience, Kings College London, Denmark Hill, London SE5 9PJ, UK

2 TCU and UNTHSC School of Medicine (applicant for LCME accreditation), Department of Medical Education, 3500 Camp Bowie Blvd., Fort Worth, TX 76107, USA

3 School of Behavioral and Brain Sciences, The University of Texas at Dallas, 800 West Campbell Road, BSB-14, Richardson, TX 75080, USA
Migraine is classified as a disabling disorder of moderate to severe throbbing head pain, with each attack lasting 4 to $72 \mathrm{~h}$, associated with nausea and/or vomiting and other sensory sensitivities [4]. Despite migraine being well recognized as a disorder of head pain among the general public, there are a wide range of nonheadache symptoms which can be associated with migraine; thus, it has become increasingly accepted as a central disorder of sensory processing; this creates a condition in which usual sensory stimuli such as light, sound, touch, and smell are perceived as more intense or bothersome, or that there is a problem with the modulation of such stimuli by the migraine brain [5]. Additionally, there can be difficulties processing such stimuli, in which the brain is unable to block "noise" of nonuseful stimuli such as peripheral conversation, a television that has been left on, or bright lighting, and migraineurs can find managing excessive amounts of such stimulation particularly difficult, for example, in loud concerts or crowds, or in flashing lighting such as at a party. Such difficulties with sensory stimulation, in some cases, are also present interictally in the absence of head pain [6], or indeed in the premonitory or postdrome phases of the attack, in which these symptoms are present without migrainous headache [7, 8]. Migraine may therefore be viewed as a primary brain disorder, in which the brain is abnormally sensitive to sensory stimulation, be that via touch, movement, light, sound, or smell, as well as subcortical and cortical brain dysfunction, so that 
activation of the process leads to a cascade of further neuronal and vascular dysfunction within the brain, mediating pain as well as other associated symptoms.

Migraine is also a disorder of trigeminovascular activation; that is, it includes activation of a pathway between sensory afferents located in the meninges and vessel walls in the cranium (the only pain sensate structures within the cranium) and neck which transfer nociceptive information through the trigeminal ganglion, cervical ganglion, and greater occipital nerve into the brain, where this information converges in the trigeminocervical complex (TCC) within the pons. From here, nociceptive signaling and modulation occur through various subcortical structures, including the rostroventral medulla (RVM), the locus coeruleus (LC), periaqueductal gray (PAG), hypothalamus, and thalamus, and eventually to the cortex for the sensory processing of pain. There is also a reflex connection from the TCC through the sphenopalatine ganglion (SPG) to the cranial vasculature, and it is thought that this pathway is likely to mediate some of the cranial autonomic symptoms that can accompany a migraine attack [9]. Despite historical views about migraine as a vascular headache and this hypothesis explaining the clinical response to triptans and dihydroergotamine as the most effective migraine abortives (mediating their action via vasoconstriction [10]), it has become increasingly clear that although the blood vessels do play a part in the disorder, migraine is much more a neural rather than vascular brain disorder, with several cortical and subcortical brain areas and ascending and descending pathways involved.

Despite decades of research into migraine, there remains a paucity of effective acute or preventive treatments available to treat the disorder. Most of the preventive treatments available were initially developed for the treatment of other conditions such as epilepsy, depression, or hypertension, and their helpful effect in migraine was noticed by chance. This means that the treatments are nonspecific and untargeted to migraine mechanisms, complicating these drugs by adverse effect profiles and tolerability issues as well as suboptimal efficacy. With regards to acute treatments, there have been no real breakthroughs in targeted abortive development since the triptans in the early 1990s [11-13], which, despite excellent efficacy in a proportion of patients, do not work for everyone [14], can be complicated by headache recurrence [15], and can cause vascular effects which are often unfavorable and contraindicate their use in anyone with preexisting cardiovascular, cerebrovascular, or peripheral vascular disease, and in anyone over the age of 65 [16]. The drugs also carry a limited license in children, and only intranasal sumatriptan is currently available for use in this group [17]. Medication overuse is another noted complication of frequent triptan use and can lead to further difficulties treating the migraine [18]. Other acute treatments used come from other pain conditions, and largely consist of nonsteroidal antiinflammatory drugs (NSAIDs) and combination drugs including those containing opioids, which pose their own problems.
There is therefore a therapeutic gap in migraine, and an ever-increasing need to develop targeted therapeutics for the condition, to limit its impact and burden without adverse effects. This can only be achieved through furthering understanding of the neurochemical systems and neurobiology of the disorder, to identify novel therapeutic targets within the migraine system, to ideally abort and/or prevent pain onset at all, and to treat associated migraine symptomatology.

\section{Introduction to Acid-Sensing lon Channels}

Acid-sensing ion channels are a family of ion channels which were first cloned in 1997 [19]. There are four members, ASIC1 to 4 (with several splice variants), three of which (all except ASIC4) are sensitive to changes in $\mathrm{pH}$ [20] (see Table 1). The channels are permeable to cations such as sodium, potassium, and in some cases calcium, and they are activated by low $\mathrm{pH}$, both intracellular and extracellular [21, 52, 53]. Additionally over recent years, there has been the suggestion that the channels can also be modulated by endogenous and external modulators [20]. The channels can detect and open at ranges of $\mathrm{pH}$ between 4.0 and $8.0[52,54]$ (ASIC3 in humans is sensitive to alkaline $\mathrm{pH}$ [52]). They are expressed throughout the human nervous system, both in the brain and spinal cord $[55,56]$. The most broadly expressed channel within the central nervous system is ASIC1 [55], particularly ASIC1a. ASIC1a is widely expressed within the mouse brain, with particular expression within the amygdala, hippocampus, PAG, caudate, putamen, olfactory bulb, cerebral cortex layer, and cerebellum [56, 57], as well as in the spinal dorsal horn neurons in rats $[22,58]$. Most ASIC subtypes are expressed on primary sensory neurons and are likely to be important for pain and mechanosensation from the skin [23]. ASIC1 and ASIC3 are highly expressed in dorsal root ganglia and in peripheral sensory neurons which supply visceral organs such as the heart and bowel as well as in muscles and joints [59-61]. See Boscardin et al. [62] for a recent review.

Maintenance of a physiological acid-base balance of cellular environments is important for normal cellular function [20]. In certain disorders, tissue acidosis can follow a range of pathological processes such as tissue ischemia and inflammation [63]. It is thought that ASICs are involved in responding to this fall in extracellular $\mathrm{pH}$ in such conditions, and thereby contribute to pathological mechanisms and cell death in response to acidosis $[24,64]$. It is postulated that on peripheral neurons, the channels are involved in sensory function such as mechanosensation and pain sensation $[65,66]$, and centrally they are likely to be involved in synaptic plasticity (with channel activation through increased proton levels caused by frequent synaptic activity) $[25,56,67,68]$. Their wide expression within the central nervous system and their role in mediating cell response to acidosis have contributed to their suggested role in human diseases, including 
Table 1 ASIC channels and subunits, and their localization and potential functions and contributions to human disease

\begin{tabular}{|c|c|c|c|c|c|}
\hline $\begin{array}{l}\text { ASIC channel } \\
\text { type }\end{array}$ & $\begin{array}{l}\mathrm{pH} \text { sensitivity }\left(\mathrm{pH}_{50}\right) \\
{[21]}\end{array}$ & $\begin{array}{l}\text { Predominant } \\
\text { localization }\end{array}$ & $\begin{array}{l}\text { Likely cellular } \\
\text { localization }\end{array}$ & Potential function & References \\
\hline ASIC1A & $5.8-6.8$ & $\begin{array}{l}\text { Central and peripheral } \\
\text { nervous systems }\end{array}$ & $\begin{array}{l}\text { Axons, cell bodies, } \\
\text { dendrites }\end{array}$ & $\begin{array}{l}\text { Cell death following injury, epilepsy, } \\
\text { pain signaling, neuroinflammation, } \\
\text { neurodegeneration, fear behavior }\end{array}$ & {$[21-35]$} \\
\hline ASIC1B & $6.1-6.2$ & $\begin{array}{l}\text { Peripheral nervous } \\
\text { system }\end{array}$ & Axons, cell bodies & & {$[21,36]$} \\
\hline ASIC2A & $4.5-4.9$ & $\begin{array}{l}\text { Central and peripheral } \\
\text { nervous systems }\end{array}$ & $\begin{array}{l}\text { Axons, cell bodies, } \\
\text { dendrites }\end{array}$ & $\begin{array}{l}\text { Modulate ASIC1, ASIC2b, and } \\
\text { ASIC3 function, autonomic } \\
\text { circulatory control }\end{array}$ & {$[21,37-40]$} \\
\hline ASIC2B & $\begin{array}{l}\text { Associates with other } \\
\text { channels to have } \\
\text { pH sensitivity }\end{array}$ & $\begin{array}{l}\text { Central and peripheral } \\
\text { nervous systems }\end{array}$ & $\begin{array}{l}\text { Axons, axons terminals, } \\
\text { cell bodies }\end{array}$ & $\begin{array}{l}\text { Modulate ASIC1 function, } \\
\text { autonomic circulatory control, } \\
\text { acidosis-induced neuronal death }\end{array}$ & {$[37,38,41]$} \\
\hline ASIC3 & $6.4-6.6$ & $\begin{array}{l}\text { Peripheral and central } \\
\text { nervous systems }\end{array}$ & $\begin{array}{l}\text { Axons, axons terminals, } \\
\text { cell bodies }\end{array}$ & $\begin{array}{l}\text { Pain signaling, fear conditioning } \\
\text { with exogenous expression, } \\
\text { anxiety and aggression }\end{array}$ & {$[21,42-50]$} \\
\hline ASIC4 & Not $\mathrm{pH}$ sensitive & $\begin{array}{l}\text { Central nervous } \\
\text { system }\end{array}$ & & $\begin{array}{l}\text { Fear and anxiety through ASIC1a } \\
\text { antagonism }\end{array}$ & {$[51]$} \\
\hline
\end{tabular}

epilepsy [26], stroke, ischemic injury [69, 70], and traumatic brain injury [71], as well as several nociceptive states [72, 73]. Through this understanding, increased research around their expression, roles, and pharmacology has subsequently led their emergence as a potential therapeutic target for such neurological disorders. Additionally, it is increasingly being recognized that they may contribute to migraine given their role in several neuronal processes linked to the disorder within the central and peripheral nervous systems.

\section{Molecular Structure of ASICs}

ASICs are either $\mathrm{Na}^{+}$- or $\mathrm{Ca}^{2+}$-permeable ion channels, are formed of three subunits, and are a part of the wider family of $\mathrm{ENaC} /$ degenerin epithelial channels, which are involved in $\mathrm{Na}^{+}$homeostasis [74] (see Fig. 1).

Although there are four main types of channel, ASIC1 to 4, subunits including ASIC1a, ASIC1b, ASIC2a, and ASIC2b also exist as splice variants, and these can form heteromultimeric channels with different functions (see Table 1). The channels are composed of three subunits that form a ligand-gated protein structure [75]. The ASIC subunits among different species are highly conserved, and human ASIC2 sequences are 99\% identical to rat ASIC2. This suggests that the protein plays an important role in neuronal function across different species.

The channel subunits are composed of 500 to 560 amino acids each, and two transmembrane domains (which line the pore of the channel) [76] with a relatively short cytoplasmic section, with 35 to 90 amino acids, with a longer extracellular domain, consisting of over 300 amino acids [77]. The proton ligand binds to the extracellular domain, which is organized in a three-dimensional structure [76]. The extracellular domain is composed of 12 beta sheets and 7 alpha helices, made of several pairs of amino acids [76]. The two long alpha helices form the transmembrane domains lining the ion pore [76]. The alpha-helix of the second transmembrane domain loosens near the selectivity filter. After the selectivity filter, the remainder of the second transmembrane domain alpha-helix fills in the lower portion of the second transmembrane domain of a neighboring subunit (see Fig. 1). The extracellular domain contains an acidic section, replete with acidic amino acids, which is involved in response to extracellular acid and response to other extracellular modulators [78] (Fig. 1).

The knowledge of this structure comes from characterization of chicken ASIC1 (PDB code 4NYK) plasma membrane (blue) and chloride ions (green) are shown. The channel is activated by protons binding to sites within the extracellular domain. Sodium and calcium ions enter the protein complex

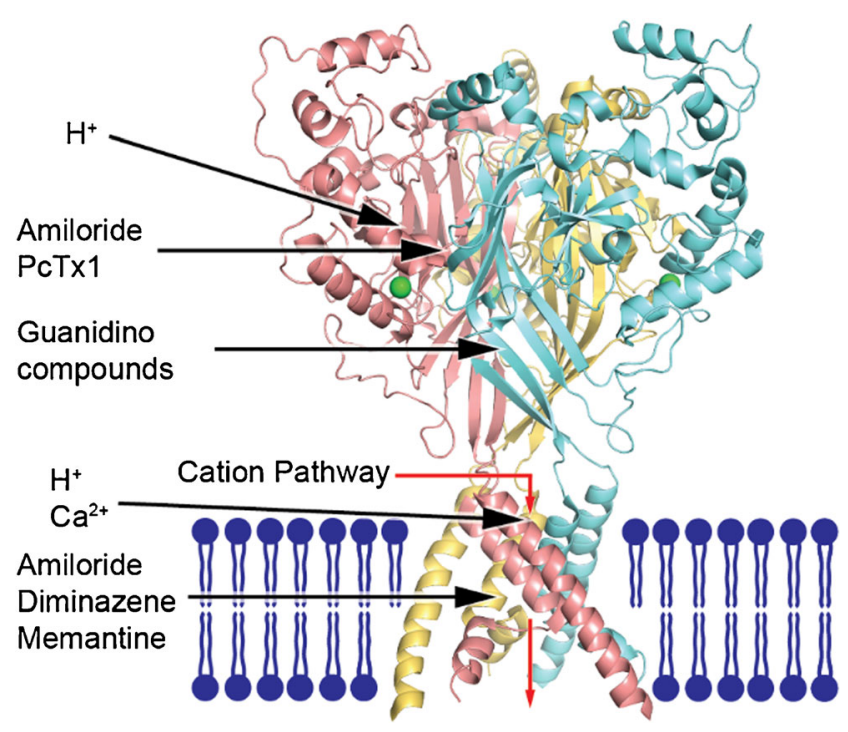

Fig. 1 Structure of an acid-sensing ion channel (in particular chicken ASIC1) 
through fenestrations at the protein/plasma membrane interface (red arrow) and pass through the pore into the cell. This leads to membrane depolarization and downstream cellular effects. Amiloride [79] and PcTx1 [80] bind to a site near the interface of two subunits in the extracellular domain. Guanidino compounds [46] may interact at an extracellular site along the channel's midline. The pore blocking sites for amiloride [79] and potential sites for diminazene [81] and memantine [82] are located within the channel pore, near the channel's selectivity filter. The three ASIC1 subunits make a trimeric ASIC1a complex. The function of the channel can also be modulated by intracellular regulators, such as p11 [83].

\section{ASICs in Neurological Disease}

ASICs have been postulated as having a role in a variety of neurological diseases, including Parkinson's disease, stroke, traumatic brain injury, multiple sclerosis, and epilepsy. Although most of the data suggesting a role for ASICs in these conditions comes from preclinical studies and animal models of human disease, their possible contribution to these diseases can provide translational insights into how they mediate cell damage and clinical syndromes.

In neurodegenerative conditions such as Parkinson's and Alzheimer's disease, mitochondrial and microglial ASICs (primarily ASIC1a) may be involved in mediating cell death $[84,85]$. ASICs may also contribute to stroke, although through a variable role in the cell response to cerebral ischemia, with ASICla activation (presumably from acidic hypoxic tissue) leading to cell death and ASIC2 being possibly protective [24]. Multiple sclerosis (MS) is another neurological disease with a potential ASIC contribution, as ASICla has been shown to be upregulated in a neuroinflammatory model, and could be responsible for axonal injury [86]. Finally, intense neuronal and synaptic activity in epilepsy causes reduced $\mathrm{pH}$ which can potentially activate ASICs and lead to seizure termination via an ASIC1a mechanism [29].

The potential contribution of ASICs to these wide-ranging neurological conditions, from neurodegeneration and excitotoxic/hypoxic cell death following ischemia and frequent synaptic activity in epilepsy, suggests that these channels may become pharmacological targets in human disease. Their wide expression and role from the cortex to deeper subcortical structures in these various conditions suggests that novel pharmaceutical agents against these channels would need to be designed to target specific ASIC subtypes under specific conditions, as there may otherwise be unwanted adverse effects associated with broad antagonism, particularly with CNS penetrant agents. Perhaps for migraine, peripherally acting agents, at the level of the trigeminal ganglion or sensory afferents (discussed below), would be sufficient for disease control.

\section{Potential Mechanisms of the ASIC Role in Migraine}

\section{Meningeal Nociceptor Activation}

Migraine pain involves the activation of dural nociceptors peripherally which then transmit pain for processing centrally [9]. Increased ASIC1 a expression has been found in the spinal dorsal horn neurons following peripheral inflammation, and antagonizing this channel reduced pain-related behavior in rodents $[22,58]$. Psalmotoxin 1 (PcTx1), a tarantula toxin, blocks the ASICla channel [87] and inhibits ASIC1a/2b current [41]. When administered intrathecally or intraventricularly, it reduced acute pain and pain-related behavior in two chronic pain models in rats [31]. Mambalgin-1, another ASIC1a antagonist but from the venom of a black mamba snake, also reduced pain behaviors in a rodent model [88]. Studies have shown that mambalgins inhibit homomeric ASIC1a, homomeric ASIC1b, and heteromeric ASIC1a + ASIC2a, ASIC1a + ASIC2b, and ASIC1a + ASIC1b receptors [89]. The heteromeric ASIC1a + ASIC2 receptor decreased acute pain and inflammatory pain in the rodent model, which was resistant to reversal by naloxone, suggesting a nonopioid analgesic effect [88]. Despite the ASIC expression and nociceptive role here being primarily spinal, there may be some role higher in the trigeminal pathway (see "New Animal Studies" section below).

In the peripheral nervous system, ASICs are expressed on sensory neurons responsible for signaling pain [23]. ASIC3 is one of the major ASICs expressed peripherally and is involved in pain originating from visceral organs such as the heart [90] and colon [59]. ASIC3 antagonists have been shown to reduce pain associated with cutaneous inflammation and pain arising from joints and muscles [45, 91].

Given that in nociceptive models, ASICs can sense acidic extracellular $\mathrm{pH}$ and cause pain as a result, it is feasible that this mechanism may be involved with the sensing of reduced meningeal $\mathrm{pH}$ in migraine [92]. Historical animal studies have demonstrated that dural afferents respond to acidic $\mathrm{pH}$ [93-95]. It has also been shown that dural stimulation leads to vasodilatation and therefore afferent trigeminal nucleus caudalis (TNC) activity, which can be blocked by amiloride, a nonselective ASIC antagonist [96]. Additionally, dural acidity leads to calcitonin gene-related peptide (CGRP) release from dural and trigeminal cell bodies and the release from trigeminal cell bodies can be blocked by a specific ASIC3 antagonist [97], suggesting a potential ASIC3-mediated role in migraine.

There is a clear role for ASICs in mediating dural afferent activity, especially since studies have shown that $80 \%$ of dural afferents will produce ASIC-like currents in response to acidic $\mathrm{pH}$ [98]. When low $\mathrm{pH}$ is directly applied to the dura of awake animals, they display headache-related behaviors which can 
be blocked at lower $\mathrm{pHs}$ by amiloride or at higher $\mathrm{pHs}$ by APETx2 (natural venom toxin from the sea anemone Anthopleura elegantissima, an ASIC3 antagonist) [94].

The mechanisms by which decreased dural $\mathrm{pH}$ may come about during the migraine process are unclear. The idea of neurogenic inflammation (a sterile meningeal inflammatory process involving several neuropeptides) occurring during migraine is a debated area [99]. However, mast cell degranulation within the dura can activate and sensitize dural afferents [100], and this degranulation is triggered by stress and CGRP release, following infusion of the nitric oxide (NO) donor nitroglycerin (NTG), and with increased estrogen [99]. Interestingly, these factors are all well-recognized potent migraine triggers in humans and one of these triggers, NO, has been shown to directly modulate ASIC activity. Cortical spreading depression (discussed below) can also lead to mast cell degranulation [101]. Mast cell granules contain acidic contents [102], and mast cell degranulation leads to the release of various proinflammatory cytokines such as interleukin-6 [103] and TNF-alpha [104], which can increase the activity and sensitivity of dural afferents to this reduction in $\mathrm{pH}$ surrounding the afferent nerve endings.

\section{Cortical Spreading Depression (CSD)}

Migraine is a complex disorder, which causes nonpainful symptoms including aura in a proportion of sufferers [105]. Aura is characterized by a reversible neurological disturbance, which may accompany a migraine attack, or may occur in isolation in the absence of headache. It has been established in the literature that the electrophysiological correlate of migraine aura is cortical spreading depression or CSD [106], which consists of a wave of neuronal excitation of the cortex, followed by a more prolonged process of neuronal depression [107]. The process of CSD leads to ion flux, neurotransmitter release, and changes in cerebral blood flow and oxygenation levels $[108,109]$. It is therefore feasible that acid-sensing ion channels may be involved in meditating this phenomenon.

It is unclear how CSD is related to the pain mechanisms in migraine, as subcortical areas and the brainstem seem to be vital to the pain of the migraine attack [9], yet the connection between CSD and such areas is disputed. Only a small proportion of migraineurs experience aura, so there are likely additional mechanisms involved in mediating migraine headache, unless CSD is clinically asymptomatic in the majority of migraineurs. Indeed, CSD can occur in other conditions and lead to aura-like symptoms in the absence of pain, including following traumatic brain injury, subarachnoid hemorrhage, epilepsy, and stroke [110], suggesting that CSD may be a process which is not immediately connected to the trigeminal pain network in migraine, but happens to be more common in migraineurs.
Preclinical studies have shown that CSD can cause cortical blood flow changes, as well as neuronal activity within the $\mathrm{TNC}$, an area where trigeminal afferent input from the face converges in the brain [111]. It has also been shown that CSD can cause increased trigeminal ganglion activity, as well as increased activity in the $\mathrm{C} 1$ to $\mathrm{C} 2$ part of the trigeminal nucleus $[112,113]$, suggesting that CSD may lead to activation within the trigeminovascular pathway and therefore lead to migraine headache. It has also been found that the release of high-mobility group box 1 (HMGB1) from cortical neurons could link CSD leading to meningeal afferent activity [101, 114]. Additionally, connections between the cortex and the TNC, a brain area vital in migraine, can modulate TNC activity, providing a mechanism by which cortical activity could impact TNC activity and therefore pain signaling through the trigeminal system [115]. However, in animal models, CSD models are not able to produce behavior consistent with head pain [116-118]. It therefore remains unclear what connection if any CSD has with pain in migraine.

It has been suggested that a reduced $\mathrm{pH}$ from CSD could lead to the propagation of the CSD across a cortical area [119, 120]. This reduced $\mathrm{pH}$ could arise from hypoxia or ischemia from vessel changes associated with the phenomenon. A study in 2006 demonstrated the ability of amiloride (a nonspecific ASIC blocker) and psalmotoxin 1 (PcTx1), a blocker at the ASIC1a and ASIC $1 \mathrm{a} / 2 \mathrm{~b}$ receptors, to inhibit CSD in a needleprick rat CSD model. This effect was reduced in ASIC1 $(-/-)$ knockout mice compared with wild type. Amiloride was also able to reduce cerebral vasodilatation in the rat model in response to electrical stimulation over the cranium, as well as to reduce electrophysiological responses to dural stimulation. As a result of this study, the authors gave amiloride, which is a licensed diuretic drug in humans, to 7 patients with treatment refractory migraine with aura and monitored them for clinical efficacy. Amiloride was able to reduce aura and headache symptoms in 4 out of 7 patients with otherwise intractable aura, suggesting a possible role for ASIC1 in migraine despite the nonselectiveness of amiloride for these channels [96].

\section{The Hypothalamus}

The role of the hypothalamus in migraine is being increasingly appreciated, following animal studies [121-123] and more recent functional imaging studies in humans [124-127]. Its role in cluster headache has been more historically established, given the cyclical nature of the disorder [128], and this role formed the basis of the research into neuromodulation and deep brain stimulation of the hypothalamus as a treatment modality for cluster headache [129-135]. It has been hypothesized that the hypothalamus could be involved in mediating some of the premonitory and endocrinological disturbances which can accompany a migraine attack, such as yawning, thirst, and altered sleep patterns, through various connections and neuromodulators 
and neurotransmitters such as orexin and somatostatin [9]. It is also well recognized that alterations in sleep patterns can trigger migraine, and this association may be mediated by the hypothalamus [122]. Serum levels of hormones investigating the hypothalamic-tuberoinfundibular system (prolactin, growth hormone), the hypothalamic-hypophyseal-adrenal axis (cortisol), and pineal gland function (melatonin) were studied and shown to be altered in chronic migraine [136].

It is also clear from animal studies that the connections from the hypothalamus terminate in recognized regions of the trigeminovascular pain pathway. There are ascending and descending connections between the hypothalamus and the trigeminocervical complex (TCC), the periaqueductal gray (PAG), the rostroventral medulla (RVM), the nucleus tractus solitarius, and the nucleus raphe magnus [137], as well as the superior salivatory nucleus (SSN) [138]. Through these various connections and brain areas, the hypothalamus is able to convey ascending nociceptive input to higher structures for processing and also to modulate descending input.

ASIC3 is expressed throughout the hypothalamus [50], and ASIC1 - and ASIC3-like currents have been demonstrated in hypothalamic neurons in culture [139]. Hypothalamic neurons also express the mRNA for various ASIC subtypes [140, 141]. Recently, it has been demonstrated that ASIC1a is expressed in lateral hypothalamic orexinergic neurons [142] and can modulate respiratory drive in a way that is blocked by ASIC antagonists. Orexinergic drugs have been researched in early trials for migraine treatment given the association between migraine and sleep and the postulated role of the hypothalamus in migraine [143]. Given the channel expressions within the hypothalamus, and the potential impact on hypothalamic function via orexinergic neurons, there is the suggestion that ASICs may play some role in migraine via the hypothalamus.

\section{The Emerging Role of ASICs in Migraine}

We have discussed above the potential ways in which ASICs could be involved in the migraine process. The majority of the data presented has been preclinical, and apart from the small open-label amiloride study in seven subjects [96], we have limited supportive human evidence for ASICs playing a role in migraine, despite convincing animal studies.

\section{New Animal Studies}

Most of the work that has been done on ASICs in migraine has focused on ASIC1, namely, ASIC1a, because of its widespread CNS expression. Emerging work which is currently unpublished but abstracted has used the demonstrated ASIC3-expressing neuronal projections to the TCC to study the role of ASIC3 inhibitors in trigeminovascular nociception. Trigeminal afferents were activated via middle meningeal artery stimulation, and extracellular recordings from the TCC were carried out. The authors demonstrated that APETx2 was able to reduce nociceptive firing in the TCC significantly more than saline with a prolonged 60 -min effect at a $100-\mathrm{mcg} / \mathrm{kg}$ dose but not at a lower dose [144]. This data suggests that ASIC3 may also be a target for migraine therapeutics.

Additional indirect support for the role of ASIC3 in migraine comes from another study in which the authors tested for the expression of ASIC1, ASIC2a, and ASIC3 in the trigeminal ganglion of rats and that there was upregulation when the rats were exposed to a formalin orofacial pain inflammatory model. Migraine can involve facial pain, and indeed can present with facial pain alone. This upregulation could be reversed with pharmacological ASIC blockade and with genetic deletion of ASIC1 [72]. This is supported in another study which showed a positive correlation between periodontal ASIC3 expression in rats following experimental tooth movement (which was conducted through springs and deemed painful on a rat grimace score) [145]. This evidence is supportive that ASIC3 may be involved broadly in trigeminal pain. Additionally, a study in 2013 showed that ASIC3 is the predominant ASIC responding to a reduced meningeal $\mathrm{pH}$ and in the context of inflammation; dural afferents are responsive to even smaller $\mathrm{pH}$ changes within the meninges, suggesting a role in headache [94]. These effects can be blocked with ASIC3 antagonism.

Further, it has recently been shown that the dural $\mathrm{pH}$ necessary to cause migraine-like behavioral responses is substantially higher if animals are first sensitized, or "primed," by prior exposure to a noxious dural stimulus. In this study, cytokine interleukin-6 (IL-6) was applied to the dura and following resolution of the initial IL- 6 behavioral responses, animals were then sensitive to stimulation of the dura with a $\mathrm{pH} 7.0$ solution. Even after sensitization, the responses to dural pH 7.0 were blocked by APETx2 indicating a role for ASIC3. Control animals did not respond to dural $\mathrm{pH} 7.0$, which demonstrates that the meninges can be sensitized to modest $\mathrm{pH}$ changes after a priming event. These findings suggest that ASIC-dependent signaling from the meninges is likely to be even more important in the context of sensitization, such as that occurring during the development of a migraine attack or even potentially in migraine patients between attacks [146].

\section{Human Imaging Work}

Acid-base changes within the brain can be detected using modern brain imaging, namely, MR proton spectroscopy. This has been used in migraine, in a hypoxia versus sham triggering model [147]. It has been known for some time that hypoxia has the potential to trigger migraine attacks [148, 149], and it has been demonstrated that hypoxia can induce 
CSD in mice and that the threshold to CSD is lower with increased CSD duration in response to potassium [150]. In healthy volunteers, hypoxia is associated with increased brain lactate [151], and this rise in lactate in association with hypoxia has also been shown in migraine with aura interictally [152]. The authors of this most recent migraine spectroscopy study therefore aimed to study the ability of hypoxia to trigger migraine with visual aura attacks; they subsequently used imaging and blood tests to measure the visual cortex concentrations of glutamate and lactate and serum metabolites in response to hypoxia versus sham in both migraine with aura and healthy controls. In both population groups, hypoxia caused increased visual cortex lactate and dilatation of the cranial vasculature, and in the migraine with aura group, hypoxia triggered aura attacks in 7 subjects out of 15 . The serum lactate was increased after hypoxia more in patients than in sham and in controls. The authors hypothesized that in migraine with aura, hypoxia may lower the threshold for CSD via lactate increases, and cause prolonged CSD. It is unclear how the increase in lactate is mediated, be it through mitochondrial dysfunction or other mechanisms. The brain responses to lactate may be mediated through ASICs, but more work is clearly necessary to address this possibility directly.

This demonstrated increase in brain lactate in response to a recognized migraine trigger suggests again that ASICs may be involved in mediating the response to lactate and therefore in mediating CSD and possibly other migraine mechanisms. Two interictal MRI studies have found increased brain lactate in patients with migraine with aura $[152,153]$ in small patient groups using 1.5-T MRI, and such findings have not been reproduced at $3 \mathrm{~T}$ in migraine without aura $[154,155]$. Additionally, a recent MRI study has demonstrated an undisrupted blood-brain barrier during spontaneous migraine with aura [156], and another study has demonstrated that a potent anti-migraine drug, dihydroergotamine (DHE), does not bind in the brain when administered in migraine without aura, suggesting that the main effect is outside of the bloodbrain barrier and that the blood-brain barrier remains intact during triggered migraine attacks [157]. These studies suggest that metabolite changes during CSD do not cause blood-brain barrier changes, and are therefore unlikely to cause the brainstem changes that occur before and during migraine headache, and that effective anti-migraine treatments do not necessarily need to penetrate the blood-brain barrier to be efficacious.

\section{ASIC Pharmacology and Reference to Migraine}

In recent years, awareness has increased about the pharmacology of ASICs and potential novel spider and venom toxins which have proved useful in experimental research to understand the role of these channels in disease. These studies are reviewed in detail in references $[158,159]$. A selection of pharmaceutical agents targeting these channels is discussed here briefly, in particular those with clinical significance for human disease.

Amiloride, which is a diuretic agent which spares potassium, was the first recognized blocker of ASICs, with broad anti-ASIC action with no differentiation between channel subtypes $[74,160]$. At higher concentrations, amiloride is able to have the paradoxical effect of opening ASIC3 homomeric and heteromeric channels at a normal $\mathrm{pH}$, and enhances the channel activation in response to mild acidosis [161]. This activity is possibly mediated at a central site between the three extracellular domains of ASIC subunits where other guanidine-containing compounds have shown efficacy $[46,162]$.

A-317567 is another ASIC antagonist that affects ASIC1a, $2 \mathrm{a}$, and 3. Furthermore, this antagonist has shown higher affinity for ASIC1a and ASIC3 compared with ASIC2a [163]. Additionally, this compound may have non-ASIC effects suggesting that other may protein targets can interact with the compound. In animals that received A-317567 in pain studies, sedation was observed. Sedation is not thought to be an ASICmediated effect, suggesting that the A-317567 compound interacts with other central nervous system receptors and has the potential for unwanted side effects [164].

Several categories of drugs that are classically used for pain can have actions at ASICs. Nonsteroidal anti-inflammatory drugs (NSAIDs) have anti-ASIC1a and ASIC3 properties [165]. Diclofenac and ibuprofen antagonize ASICs expressed in rat hippocampal interneurons [166]. However, these antiASIC1a and ASIC3 effects are at higher concentrations than the effects observed with lower concentrations of amiloride. Whereas most local anesthetics exert their anti-nociceptive effect through sodium channels, some have been shown to have anti-ASIC properties, including tetracaine on ASIC3 [167], lidocaine on ASIC1a [168], and the general anesthetic propofol on ASICla and ASIC3 [169].

Clinically approved and available compounds for other diseases may also have ASIC modulatory effects. One example is the drug memantine, a hydrophobic monoamine that targets ionotropic glutamate receptors for treating dementia associated with Alzheimer's disease [82]. Memantine inhibits ASIC1a in both neurons and cultured cells [170]. Furthermore, memantine was shown to antagonize the channel at hyperpolarized voltages but potentiated (increased) ASIC1a-mediated current at zero voltage [82]. Modeling data suggests that memantine blocks the channel deep within the ASIC1a pore. However, the site within ASIC1a responsible for potentiation by memantine remains unclear.

Finally, there are compounds that perhaps surprisingly have effects at ASICs, and these effects may not play a role 
in their primary mechanism of action. For example, the anti-protozoan compound diminazene exhibited antihyperalgesic activity in models of chronic inflammatory pain [171]. Diminazine acts as a channel blocker for ASICs [81, 171], and although this action may contribute to its efficacy for pain, it is unclear whether this mediates its effects on protozoa. Nonetheless, this example illustrates the possibility that modulators of ASICs will be discovered through screening of currently existing compounds that are used for other purposes.

\section{ASICs in Migraine Drug Development}

We have outlined in this review the preclinical and clinical evidence supporting the role of ASICs in migraine. From the evidence presented so far, it is likely that there are two predominant roles, 1) in the modulation of CSD and therefore migraine aura, in particular with the evidence supporting ASIC1a, and 2) in the modulation of nociceptive signaling from the meninges, in which there is the emerging role for ASIC3 in trigeminovascular nociception. It is clear that this is an evolving field, and more understanding and research is needed to understand the various ASIC subtypes and their potential roles in human disease.

Unfortunately, there are currently no ASIC subtypespecific antagonists which are available for safe use in humans, and the use of amiloride is limited by its lack of specificity; it has actions at non-ASIC receptors, as well as broad ASIC antagonism. However, understanding brain metabolism during migraine attacks using functional imaging, and further imaging of aura in migraineurs, may provide us with additional understanding of how changes in $\mathrm{pH}$ and subsequently ASIC activity may contribute to CSD. Additionally, further preclinical models of both aura and trigeminovascular activation and use of ASIC subtype-selective antagonists are likely to provide further valuable insights into the mechanisms by which these channels may be involved in migraine headache.

As discussed earlier, their wide CNS and PNS expression makes ASICs attractive therapeutic targets. However, simultaneous disruption of various channel subtypes may lead to unexpected effects. Targeted therapies (perhaps against ASIC1a and ASIC3) are likely to be more useful and yield fewer unwanted adverse effects. Peripherally acting agents may be sufficient in migraine, given recent evidence from the DHE study which suggests no or limited blood-brain barrier permeability of this efficacious abortive in migraine therapy [157], and the likely peripheral sites of action of the novel anti-calcitonin gene-related peptide (CGRP) therapies, which have shown clinical efficacy both acutely and preventively and are in late-phase clinical trials [172].

\section{Conclusions}

We have discussed here the broad range of preclinical and clinical research which supports a potential role of ASICs in nociception, as well as other neurological conditions. There is increasing evidence for their role in migraine, and it is likely that further animal work, human genetics, and functional imaging in migraine patients may help us refine the contribution of these channels to the disorder. In an era in which there is an ever-increasing need for effective therapies for migraine, which is a disabling condition usually affecting otherwise fit and well young individuals, ASICs provide an attractive potential therapeutic target, perhaps particularly so in migraine with aura. Their role in migraine, once better understood, could well be extrapolated to other CNS conditions which may share some common mechanisms, such as symptomatic CSD following traumatic brain injury or stroke, providing a useful treatment strategy for these conditions also.

Required Author Forms Disclosure forms provided by the authors are available with the online version of this article.

Open Access This article is distributed under the terms of the Creative Commons Attribution 4.0 International License (http:// creativecommons.org/licenses/by/4.0/), which permits unrestricted use, distribution, and reproduction in any medium, provided you give appropriate credit to the original author(s) and the source, provide a link to the Creative Commons license, and indicate if changes were made.

\section{References}

1. Global, regional, and national incidence, prevalence, and years lived with disability for 301 acute and chronic diseases and injuries in 188 countries, 1990-2013: a systematic analysis for the Global Burden of Disease Study 2013. Lancet 2015;386(9995): 743-800.

2. Lipton RB, Bigal ME, Diamond M, Freitag F, Reed ML, Stewart WF. Migraine prevalence, disease burden, and the need for preventive therapy. Neurology 2007;68(5):343-9.

3. Buse DC, Manack A, Serrano D, Turkel C, Lipton RB. Sociodemographic and comorbidity profiles of chronic migraine and episodic migraine sufferers. J Neurol Neurosurg Psychiatry 2010;81(4):428-32.

4. The International Classification of Headache Disorders, 3rd edition (beta version). Cephalalgia 2013;33(9):629-808.

5. Goadsby PJ, Holland PR, Martins-Oliveira M, Hoffmann J, Schankin C, Akerman S. Pathophysiology of migraine: a disorder of sensory processing. Physiol Rev 2017;97(2):553-622.

6. Demarquay G, Mauguiere F. Central nervous system underpinnings of sensory hypersensitivity in migraine: insights from neuroimaging and electrophysiological studies. Headache 2016;56(9):1418-38.

7. Giffin NJ, Lipton RB, Silberstein SD, Olesen J, Goadsby PJ. The migraine postdrome: an electronic diary study. Neurology 2016;87(3):309-13. 
8. Giffin NJ, Ruggiero L, Lipton RB, Silberstein SD, Tvedskov JF, Olesen J, et al. Premonitory symptoms in migraine: an electronic diary study. Neurology 2003;60(6):935-40.

9. Akerman S, Holland PR, Goadsby PJ. Diencephalic and brainstem mechanisms in migraine. Nat Rev Neurol 2011;12:570-84.

10. Speed WG, 3rd. Ergotamine tartrate inhalation: a new approach to the management of recurrent vascular headaches. Am J Med Sci 1960;240:327-31.

11. Doenicke A, Brand J, Perrin VL. Possible benefit of GR43175, a novel 5-HT1-like receptor agonist, for the acute treatment of severe migraine. Lancet 1988;1(8598):1309-11.

12. Cady RK, Wendt JK, Kirchner JR, Sargent JD, Rothrock JF, Skaggs H, Jr. Treatment of acute migraine with subcutaneous sumatriptan. JAMA 1991;265(21):2831-5.

13. Goadsby PJ, Zagami AS, Donnan GA, Symington G, Anthony M, Bladin PF, et al. Oral sumatriptan in acute migraine. Lancet 1991;338(8770):782-3.

14. Velati D, Viana M, Cresta S, Mantegazza P, Testa L, Bettucci D, et al. 5-hydroxytryptamine1B receptor and triptan response in migraine, lack of association with common polymorphisms. Eur J Pharmacol 2008;580(1-2):43-7.

15. Sheftell F, Almas M, Weeks R, Mathew NT, Pitman V, Lipton RB. Quantifying the return of headache in triptan-treated migraineurs: an observational study. Cephalalgia 2010;30(7):838-46.

16. Dodick D, Lipton RB, Martin V, Papademetriou V, Rosamond W, MaassenVanDenBrink A, et al. Consensus statement: cardiovascular safety profile of triptans (5-HT agonists) in the acute treatment of migraine. Headache 2004;44(5):414-25.

17. Callenbach PM, Pels LP, Mulder PG, Linssen WH, Gooskens RH, van der Zwan JL, et al. Sumatriptan nasal spray in the acute treatment of migraine in adolescents and children. Eur J Paediatr Neurol 2007;11(6):325-30.

18. Thorlund K, Sun-Edelstein C, Druyts E, Kanters S, Ebrahim S, Bhambri R, et al. Risk of medication overuse headache across classes of treatments for acute migraine. J Headache Pain 2016;17(1):107.

19. Waldmann R, Champigny G, Bassilana F, Heurteaux C, Lazdunski M. A proton-gated cation channel involved in acidsensing. Nature 1997;386(6621):173-7.

20. Wemmie JA, Taugher RJ, Kreple CJ. Acid-sensing ion channels in pain and disease. Nat Rev Neurosci 2013;14(7):461-71.

21. Hesselager M, Timmermann DB, Ahring PK. pH Dependency and desensitization kinetics of heterologously expressed combinations of acid-sensing ion channel subunits. J Biol Chem 2004;279(12):11006-15.

22. Duan B, Wu LJ, Yu YQ, Ding Y, Jing L, Xu L, et al. Upregulation of acid-sensing ion channel ASIC1a in spinal dorsal horn neurons contributes to inflammatory pain hypersensitivity. J Neurosci 2007;27(41):11139-48.

23. Alvarez de la Rosa D, Krueger SR, Kolar A, Shao D, Fitzsimonds RM, Canessa CM. Distribution, subcellular localization and ontogeny of ASIC1 in the mammalian central nervous system. J Physiol 2003;546(Pt 1):77-87.

24. Xiong ZG, Zhu XM, Chu XP, Minami M, Hey J, Wei WL, et al. Neuroprotection in ischemia: blocking calcium-permeable acidsensing ion channels. Cell 2004;118(6):687-98.

25. Mazzone GL, Veeraraghavan P, Gonzalez-Inchauspe C, Nistri A, Uchitel OD. ASIC channel inhibition enhances excitotoxic neuronal death in an in vitro model of spinal cord injury. Neuroscience 2017;343:398-410.

26. Lv RJ, He JS, Fu YH, Zhang YQ, Shao XQ, Wu LW, et al. ASIC1 a polymorphism is associated with temporal lobe epilepsy. Epilepsy Res 2011;96(1-2):74-80.

27. Coryell MW, Wunsch AM, Haenfler JM, Allen JE, McBride JL, Davidson BL, et al. Restoring Acid-sensing ion channel-1a in the amygdala of knock-out mice rescues fear memory but not unconditioned fear responses. J Neurosci 2008;28(51):13738-41.

28. Ziemann AE, Allen JE, Dahdaleh NS, Drebot, II, Coryell MW, Wunsch AM, et al. The amygdala is a chemosensor that detects carbon dioxide and acidosis to elicit fear behavior. Cell 2009;139(5):1012-21.

29. Ziemann AE, Schnizler MK, Albert GW, Severson MA, Howard MA, 3rd, Welsh MJ, et al. Seizure termination by acidosis depends on ASIC1a. Nat Neurosci 2008;11(7):816-22.

30. Wemmie JA, Coryell MW, Askwith CC, Lamani E, Leonard AS, Sigmund CD, et al. Overexpression of acid-sensing ion channel 1a in transgenic mice increases acquired fear-related behavior. Proc Natl Acad Sci U S A 2004;101(10):3621-6.

31. Mazzuca M, Heurteaux C, Alloui A, Diochot S, Baron A, Voilley $\mathrm{N}$, et al. A tarantula peptide against pain via ASIC1a channels and opioid mechanisms. Nat Neurosci 2007;10(8):943-5.

32. Friese MA, Craner MJ, Etzensperger R, Vergo S, Wemmie JA, Welsh MJ, et al. Acid-sensing ion channel-1 contributes to axonal degeneration in autoimmune inflammation of the central nervous system. Nat Med 2007;13(12):1483-9.

33. Hu R, Duan B, Wang D, Yu Y, Li W, Luo H, et al. Role of acidsensing ion channel 1a in the secondary damage of traumatic spinal cord injury. Ann Surg 2011;254(2):353-62.

34. Pignataro G, Simon RP, Xiong ZG. Prolonged activation of ASIC1a and the time window for neuroprotection in cerebral ischaemia. Brain 2007;130(Pt 1):151-8.

35. Aissouni Y, El Guerrab A, Hamieh AM, Ferrier J, Chalus M, Lemaire $\mathrm{D}$, et al. Acid-sensing ion channel $1 \mathrm{a}$ in the amygdala is involved in pain and anxiety-related behaviours associated with arthritis. Sci Rep 2017;7:43617.

36. Bassler EL, Ngo-Anh TJ, Geisler HS, Ruppersberg JP, Grunder S. Molecular and functional characterization of acid-sensing ion channel (ASIC) 1b. J Biol Chem 2001;276(36):33782-7.

37. Lu Y, Ma X, Sabharwal R, Snitsarev V, Morgan D, Rahmouni K, et al. The ion channel ASIC2 is required for baroreceptor and autonomic control of the circulation. Neuron 2009;64(6):885-97.

38. Askwith CC, Wemmie JA, Price MP, Rokhlina T, Welsh MJ. Acid-sensing ion channel 2 (ASIC2) modulates ASIC1 H+-activated currents in hippocampal neurons. J Biol Chem 2004;279(18):18296-305.

39. Kweon HJ, Cho JH, Jang IS, Suh BC. ASIC2a-dependent increase of ASIC3 surface expression enhances the sustained component of the currents. BMB Rep 2016;49(10):542-7.

40. Kweon HJ, Kim DI, Bae Y, Park JY, Suh BC. Acid-sensing ion channel 2a (ASIC2a) promotes surface trafficking of ASIC2b via heteromeric assembly. Sci Rep 2016;6:30684.

41. Sherwood TW, Lee KG, Gormley MG, Askwith CC. Heteromeric acid-sensing ion channels (ASICs) composed of ASIC2b and ASIC1a display novel channel properties and contribute to acidosis-induced neuronal death. J Neurosci 2011;31(26):972334.

42. Fromy B, Lingueglia E, Sigaudo-Roussel D, Saumet JL, Lazdunski M. Asic3 is a neuronal mechanosensor for pressureinduced vasodilation that protects against pressure ulcers. Nat Med 2012;18(8):1205-7.

43. Vralsted VC, Price MP, Du J, Schnizler M, Wunsch AM, Ziemann $\mathrm{AE}$, et al. Expressing acid-sensing ion channel 3 in the brain alters acid-evoked currents and impairs fear conditioning. Genes Brain Behav 2011;10(4):444-50.

44. Chen CC, Zimmer A, Sun WH, Hall J, Brownstein MJ, Zimmer A. A role for ASIC3 in the modulation of high-intensity pain stimuli. Proc Natl Acad Sci U S A 2002;99(13):8992-7.

45. Deval E, Noel J, Lay N, Alloui A, Diochot S, Friend V, et al. ASIC3, a sensor of acidic and primary inflammatory pain. EMBO J 2008;27(22):3047-55. 
46. Yu Y, Chen Z, Li WG, Cao H, Feng EG, Yu F, et al. A nonproton ligand sensor in the acid-sensing ion channel. Neuron 2010;68(1): 61-72.

47. Wang X, Li WG, Yu Y, Xiao X, Cheng J, Zeng WZ, et al. Serotonin facilitates peripheral pain sensitivity in a manner that depends on the nonproton ligand sensing domain of ASIC 3 channel. J Neurosci 2013;33(10):4265-79.

48. Wu WL, Lin YW, Min MY, Chen CC. Mice lacking Asic3 show reduced anxiety-like behavior on the elevated plus maze and reduced aggression. Genes Brain Behav 2010;9(6):603-14.

49. Cao Q, Wang W, Gu J, Jiang G, Wang K, Xu Z, et al. Elevated expression of acid-sensing ion channel 3 inhibits epilepsy via activation of interneurons. Mol Neurobiol 2016;53(1):485-98.

50. Meng QY, Wang W, Chen XN, Xu TL, Zhou JN. Distribution of acid-sensing ion channel 3 in the rat hypothalamus. Neuroscience 2009;159(3):1126-34.

51. Lin SH, Chien YC, Chiang WW, Liu YZ, Lien CC, Chen CC. Genetic mapping of ASIC4 and contrasting phenotype to ASICla in modulating innate fear and anxiety. Eur J Neurosci 2015;41(12):1553-68.

52. Delaunay A, Gasull X, Salinas M, Noel J, Friend V, Lingueglia E, et al. Human ASIC3 channel dynamically adapts its activity to sense the extracellular $\mathrm{pH}$ in both acidic and alkaline directions. Proc Natl Acad Sci U S A 2012;109(32):13124-9.

53. Wang WZ, Chu XP, Li MH, Seeds J, Simon RP, Xiong ZG. Modulation of acid-sensing ion channel currents, acid-induced increase of intracellular $\mathrm{Ca} 2+$, and acidosis-mediated neuronal injury by intracellular pH. J Biol Chem 2006;281(39):29369-78.

54. Deval E, Gasull X, Noel J, Salinas M, Baron A, Diochot S, et al. Acid-sensing ion channels (ASICs): pharmacology and implication in pain. Pharmacol Ther 2010;128(3):549-58.

55. Grunder S, Chen X. Structure, function, and pharmacology of acid-sensing ion channels (ASICs): focus on ASIC1a. Int J Physiol Pathophysiol Pharmacol 2010;2(2):73-94.

56. Wemmie JA, Askwith CC, Lamani E, Cassell MD, Freeman JH, Jr., Welsh MJ. Acid-sensing ion channel 1 is localized in brain regions with high synaptic density and contributes to fear conditioning. J Neurosci 2003;23(13):5496-502.

57. Coryell MW, Ziemann AE, Westmoreland PJ, Haenfler JM, Kurjakovic Z, Zha XM, et al. Targeting ASICla reduces innate fear and alters neuronal activity in the fear circuit. Biol Psychiatry 2007;62(10):1140-8.

58. Wu LJ, Duan B, Mei YD, Gao J, Chen JG, Zhuo M, et al. Characterization of acid-sensing ion channels in dorsal horn neurons of rat spinal cord. J Biol Chem 2004;279(42):43716-24.

59. Page AJ, Brierley SM, Martin CM, Price MP, Symonds E, Butler $\mathrm{R}$, et al. Different contributions of ASIC channels 1a, 2, and 3 in gastrointestinal mechanosensory function. Gut 2005;54(10): 1408-15.

60. Sutherland SP, Benson CJ, Adelman JP, McCleskey EW. Acidsensing ion channel 3 matches the acid-gated current in cardiac ischemia-sensing neurons. Proc Natl Acad Sci U S A 2001;98(2): $711-6$.

61. Ikeuchi M, Kolker SJ, Sluka KA. Acid-sensing ion channel 3 expression in mouse knee joint afferents and effects of carrageenan-induced arthritis. J Pain 2009;10(3):336-42.

62. Boscardin E, Alijevic O, Hummler E, Frateschi S, Kellenberger S. The function and regulation of acid-sensing ion channels (ASICs) and the epithelial $\mathrm{Na}(+)$ channel $(\mathrm{ENaC})$ : IUPHAR Review $19 . \mathrm{Br}$ J Pharmacol 2016;173(18):2671-701.

63. Zeng WZ, Xu TL. Proton production, regulation and pathophysiological roles in the mammalian brain. Neurosci Bull 2012;28(1): $1-13$.

64. Yermolaieva O, Leonard AS, Schnizler MK, Abboud FM, Welsh MJ. Extracellular acidosis increases neuronal cell calcium by activating acid-sensing ion channel 1a. Proc Natl Acad Sci U S A 2004;101(17):6752-7.

65. Price MP, Lewin GR, McIlwrath SL, Cheng C, Xie J, Heppenstall $\mathrm{PA}$, et al. The mammalian sodium channel $\mathrm{BNC} 1$ is required for normal touch sensation. Nature 2000;407(6807):1007-11.

66. Price MP, McIlwrath SL, Xie J, Cheng C, Qiao J, Tarr DE, et al. The DRASIC cation channel contributes to the detection of cutaneous touch and acid stimuli in mice. Neuron 2001;32(6):107183.

67. Kreple CJ, Lu Y, Taugher RJ, Schwager-Gutman AL, Du J, Stump $\mathrm{M}$, et al. Acid-sensing ion channels contribute to synaptic transmission and inhibit cocaine-evoked plasticity. Nat Neurosci 2014;17(8):1083-91.

68. Wemmie JA, Chen J, Askwith CC, Hruska-Hageman AM, Price MP, Nolan BC, et al. The acid-activated ion channel ASIC contributes to synaptic plasticity, learning, and memory. Neuron 2002;34(3):463-77.

69. Li MH, Leng TD, Feng XC, Yang T, Simon RP, Xiong ZG. Modulation of acid-sensing ion channel 1a by intracellular $\mathrm{pH}$ and its role in ischemic stroke. J Biol Chem 2016;291(35): 18370-83.

70. Bhowmick S, Moore JT, Kirschner DL, Curry MC, Westbrook EG, Rasley BT, et al. Acidotoxicity via ASICla mediates cell death during oxygen glucose deprivation and abolishes excitotoxicity. ACS chemical neuroscience. 2017.

71. Yin T, Lindley TE, Albert GW, Ahmed R, Schmeiser PB, Grady MS, et al. Loss of acid sensing ion channel-1a and bicarbonate administration attenuate the severity of traumatic brain injury. PLoS One 2013;8(8):e72379.

72. Fu H, Fang P, Zhou HY, Zhou J, Yu XW, Ni M, et al. Acid-sensing ion channels in trigeminal ganglion neurons innervating the orofacial region contribute to orofacial inflammatory pain. Clin Exp Pharmacol Physiol 2016;43(2):193-202.

73. Sluka KA, Gregory NS. The dichotomized role for acid sensing ion channels in musculoskeletal pain and inflammation. Neuropharmacology 2015;94:58-63.

74. Waldmann R, Champigny G, Voilley N, Lauritzen I, Lazdunski $\mathrm{M}$. The mammalian degenerin MDEG, an amiloride-sensitive cation channel activated by mutations causing neurodegeneration in Caenorhabditis elegans. J Biol Chem 1996;271(18):10433-6.

75. Waldmann R, Lazdunski M. H(+)-gated cation channels: neuronal acid sensors in the NaC/DEG family of ion channels. Curr Opin Neurobiol 1998;8(3):418-24.

76. Jasti J, Furukawa H, Gonzales EB, Gouaux E. Structure of acidsensing ion channel 1 at $1.9 \mathrm{~A}$ resolution and low $\mathrm{pH}$. Nature 2007;449(7160):316-23.

77. Saugstad JA, Roberts JA, Dong J, Zeitouni S, Evans RJ. Analysis of the membrane topology of the acid-sensing ion channel 2a. J Biol Chem 2004;279(53):55514-9.

78. Gonzales EB, Kawate T, Gouaux E. Pore architecture and ion sites in acid-sensing ion channels and $\mathrm{P} 2 \mathrm{X}$ receptors. Nature 2009:460(7255):599-604.

79. Baconguis I, Bohlen CJ, Goehring A, Julius D, Gouaux E. X-ray structure of acid-sensing ion channel 1-snake toxin complex reveals open state of a $\mathrm{Na}(+)$-selective channel. Cell 2014;156(4): 717-29.

80. Baconguis I, Gouaux E. Structural plasticity and dynamic selectivity of acid-sensing ion channel-spider toxin complexes. Nature 2012;489(7416):400-5.

81. Schmidt A, Rossetti G, Joussen S, Grunder S. Diminazene is a slow pore blocker of acid-sensing ion channel 1a (ASIC1a). Mol Pharmacol 2017;92(6):665-75.

82. Shteinikov VY, Tikhonova TB, Korkosh VS, Tikhonov DB. Potentiation and block of ASICla by memantine. Cellular and molecular neurobiology. 2017. 
83. Zha XM. Acid-sensing ion channels: trafficking and synaptic function. Mol Brain 2013;6:1.

84. Wang YZ, Zeng WZ, Xiao X, Huang Y, Song XL, Yu Z, et al. Intracellular ASIC1a regulates mitochondrial permeability transition-dependent neuronal death. Cell Death Differ 2013;20(10):1359-69.

85. Yu XW, Hu ZL, Ni M, Fang P, Zhang PW, Shu Q, et al. Acidsensing ion channels promote the inflammation and migration of cultured rat microglia. Glia 2015;63(3):483-96.

86. Arun T, Tomassini V, Sbardella E, de Ruiter MB, Matthews L, Leite MI, et al. Targeting ASIC1 in primary progressive multiple sclerosis: evidence of neuroprotection with amiloride. Brain 2013;136(Pt 1):106-15.

87. Escoubas P, De Weille JR, Lecoq A, Diochot S, Waldmann R, Champigny $\mathrm{G}$, et al. Isolation of a tarantula toxin specific for a class of proton-gated Na+ channels. J Biol Chem 2000;275(33): 25116-21.

88. Diochot S, Baron A, Salinas M, Douguet D, Scarzello S, DabertGay AS, et al. Black mamba venom peptides target acid-sensing ion channels to abolish pain. Nature 2012;490(7421):552-5.

89. Mourier G, Salinas M, Kessler P, Stura EA, Leblanc M, Tepshi L, et al. Mambalgin-1 pain-relieving peptide, stepwise solid-phase synthesis, crystal structure, and functional domain for acidsensing ion channel 1a inhibition. J Biol Chem 2016;291(6): 2616-29.

90. Yagi J, Wenk HN, Naves LA, McCleskey EW. Sustained currents through ASIC3 ion channels at the modest $\mathrm{pH}$ changes that occur during myocardial ischemia. Circ Res 2006;99(5):501-9.

91. Deval E, Noel J, Gasull X, Delaunay A, Alloui A, Friend V, et al. Acid-sensing ion channels in postoperative pain. J Neurosci 2011;31(16):6059-66.

92. Burstein R. Deconstructing migraine headache into peripheral and central sensitization. Pain 2001;89(2-3):107-10.

93. Burstein R, Yamamura H, Malick A, Strassman AM. Chemical stimulation of the intracranial dura induces enhanced responses to facial stimulation in brain stem trigeminal neurons. J Neurophysiol 1998;79(2):964-82.

94. Yan J, Wei X, Bischoff C, Edelmayer RM, Dussor G. pH-evoked dural afferent signaling is mediated by ASIC 3 and is sensitized by mast cell mediators. Headache 2013;53(8):1250-61.

95. Bove GM, Moskowitz MA. Primary afferent neurons innervating guinea pig dura. J Neurophysiol 1997;77(1):299-308.

96. Holland PR, Akerman S, Andreou AP, Karsan N, Wemmie JA, Goadsby PJ. Acid-sensing ion channel 1: a novel therapeutic target for migraine with aura. Ann Neurol 2012;72(4):559-63.

97. Durham PL, Masterson CG. Two mechanisms involved in trigeminal CGRP release: implications for migraine treatment. Headache 2013;53(1):67-80.

98. Yan J, Edelmayer RM, Wei X, De Felice M, Porreca F, Dussor G. Dural afferents express acid-sensing ion channels: a role for decreased meningeal pH in migraine headache. Pain 2011;152(1): 106-13.

99. Levy D. Migraine pain, meningeal inflammation, and mast cells. Curr Pain Headache Rep 2009;13(3):237-40.

100. Levy D, Burstein R, Kainz V, Jakubowski M, Strassman AM. Mast cell degranulation activates a pain pathway underlying migraine headache. Pain 2007;130(1-2):166-76.

101. Karatas H, Erdener SE, Gursoy-Ozdemir Y, Lule S, Eren-Kocak $\mathrm{E}$, Sen ZD, et al. Spreading depression triggers headache by activating neuronal Panx1 channels. Science (New York, NY). 2013;339(6123):1092-5.

102. De Young MB, Nemeth EF, Scarpa A. Measurement of the internal $\mathrm{pH}$ of mast cell granules using microvolumetric fluorescence and isotopic techniques. Arch Biochem Biophys 1987;254(1): $222-33$.
103. Yan J, Melemedjian OK, Price TJ, Dussor G. Sensitization of dural afferents underlies migraine-related behavior following meningeal application of interleukin-6 (IL-6). Mol Pain 2012;8:6.

104. Zhang XC, Kainz V, Burstein R, Levy D. Tumor necrosis factoralpha induces sensitization of meningeal nociceptors mediated via local COX and p38 MAP kinase actions. Pain 2011;152(1):140-9.

105. Headache Classification Committee of the International Headache Society The International Classification of Headache Disorders, 3rd edition (beta version). Cephalalgia : an international journal of headache. 2013;33(9):629-808.

106. Lauritzen M, Jorgensen MB, Diemer NH, Gjedde A, Hansen AJ. Persistent oligemia of rat cerebral cortex in the wake of spreading depression. Ann Neurol 1982;12(5):469-74.

107. Leao A. Spreading depression of activity in the cerebral cortex. J Neurophysiol 1944;7(6):359-90.

108. Herreras O, Somjen GG. Analysis of potential shifts associated with recurrent spreading depression and prolonged unstable spreading depression induced by microdialysis of elevated $\mathrm{K}+$ in hippocampus of anesthetized rats. Brain Res 1993;610(2):283-94.

109. Enger R, Tang W, Vindedal GF, Jensen V, Johannes Helm P, Sprengel R, et al. Dynamics of ionic shifts in cortical spreading depression. Cerebral Cortex (New York, NY: 1991). 2015;25(11): 4469-76.

110. Lauritzen M, Dreier JP, Fabricius M, Hartings JA, Graf R, Strong AJ. Clinical relevance of cortical spreading depression in neurological disorders: migraine, malignant stroke, subarachnoid and intracranial hemorrhage, and traumatic brain injury. J Cereb Blood Flow Metab 2011;31(1):17-35.

111. Bolay H, Reuter U, Dunn AK, Huang Z, Boas DA, Moskowitz MA. Intrinsic brain activity triggers trigeminal meningeal afferents in a migraine model. Nat Med 2002;8(2):136-42.

112. Zhang X, Levy D, Kainz V, Noseda R, Jakubowski M, Burstein R. Activation of central trigeminovascular neurons by cortical spreading depression. Ann Neurol 2011;69(5):855-65.

113. Zhang X, Levy D, Noseda R, Kainz V, Jakubowski M, Burstein R. Activation of meningeal nociceptors by cortical spreading depression: implications for migraine with aura. J Neurosci 2010;30(26): 8807-14.

114. Noseda R, Kainz V, Jakubowski M, Gooley JJ, Saper CB, Digre $\mathrm{K}$, et al. A neural mechanism for exacerbation of headache by light. Nat Neurosci 2010;13(2):239-45.

115. Noseda R, Constandil L, Bourgeais L, Chalus M, Villanueva L. Changes of meningeal excitability mediated by corticotrigeminal networks: a link for the endogenous modulation of migraine pain. J Neurosci 2010;30(43):14420-9.

116. Fioravanti B, Kasasbeh A, Edelmayer R, Skinner DP, Jr., Hartings $\mathrm{JA}$, Burklund RD, et al. Evaluation of cutaneous allodynia following induction of cortical spreading depression in freely moving rats. Cephalalgia 2011;31(10):1090-100.

117. Ebersberger A, Schaible HG, Averbeck B, Richter F. Is there a correlation between spreading depression, neurogenic inflammation, and nociception that might cause migraine headache? Ann Neurol 2001;49(1):7-13.

118. Lambert GA, Michalicek J, Storer RJ, Zagami AS. Effect of cortical spreading depression on activity of trigeminovascular sensory neurons. Cephalalgia 1999;19(7):631-8.

119. Pietrobon D, Moskowitz MA. Chaos and commotion in the wake of cortical spreading depression and spreading depolarizations. Nat Rev Neurosci 2014;15(6):379-93.

120. Somjen GG. Mechanisms of spreading depression and hypoxic spreading depression-like depolarization. Physiol Rev 2001;81(3):1065-96.

121. Charbit AR, Akerman S, Goadsby PJ. Trigeminocervical complex responses after lesioning dopaminergic A11 nucleus are modified by dopamine and serotonin mechanisms. Pain 2011;152(10): 2365-76. 
122. Holland PR. Headache and sleep: shared pathophysiological mechanisms. Cephalalgia 2014;34(10):725-44.

123. Martins-Oliveira M, Akerman S, Holland PR, Hoffmann JR, Tavares I, Goadsby PJ. Neuroendocrine signaling modulates specific neural networks relevant to migraine. Neurobiol Dis 2017;101:16-26.

124. Schulte LH, May A. The migraine generator revisited: continuous scanning of the migraine cycle over 30 days and three spontaneous attacks. Brain J Neurol 2016;139(Pt 7):1987-93.

125. Maniyar FH, Sprenger T, Monteith T, Schankin C, Goadsby PJ. Brain activations in the premonitory phase of nitroglycerintriggered migraine attacks. Brain J Neurol 2014;137(Pt 1):232-41.

126. Schulte LH, Allers A, May A. Hypothalamus as a mediator of chronic migraine: evidence from high-resolution fMRI. Neurology 2017;88(21):2011-6.

127. Moulton EA, Becerra L, Johnson A, Burstein R, Borsook D. Altered hypothalamic functional connectivity with autonomic circuits and the locus coeruleus in migraine. PLoS One 2014;9(4): e95508.

128. May A, Bahra A, Buchel C, Frackowiak RS, Goadsby PJ. Hypothalamic activation in cluster headache attacks. Lancet 1998;352(9124):275-8.

129. Franzini A, Ferroli P, Leone M, Broggi G. Stimulation of the posterior hypothalamus for treatment of chronic intractable cluster headaches: first reported series. Neurosurgery 2003;52(5):10959; discussion 9-101.

130. Leone M, Franzini A, Broggi G, Bussone G. Hypothalamic deep brain stimulation for intractable chronic cluster headache: a 3-year follow-up. Neurol Sci 2003;24 Suppl 2:S143-5.

131. Schoenen J, Di Clemente L, Vandenheede M, Fumal A, De Pasqua $\mathrm{V}$, Mouchamps M, et al. Hypothalamic stimulation in chronic cluster headache: a pilot study of efficacy and mode of action. Brain 2005;128(Pt 4):940-7.

132. Starr PA, Barbaro NM, Raskin NH, Ostrem JL. Chronic stimulation of the posterior hypothalamic region for cluster headache: technique and 1-year results in four patients. J Neurosurg 2007;106(6):999-1005.

133. Bartsch T, Pinsker MO, Rasche D, Kinfe T, Hertel F, Diener HC, et al. Hypothalamic deep brain stimulation for cluster headache: experience from a new multicase series. Cephalalgia 2008;28(3): $285-95$.

134. Fontaine D, Lazorthes Y, Mertens P, Blond S, Geraud G, Fabre N, et al. Safety and efficacy of deep brain stimulation in refractory cluster headache: a randomized placebo-controlled double-blind trial followed by a 1 -year open extension. J Headache Pain 2010;11(1):23-31.

135. Seijo F, Saiz A, Lozano B, Santamarta E, Alvarez-Vega M, Seijo E, et al. Neuromodulation of the posterolateral hypothalamus for the treatment of chronic refractory cluster headache: Experience in five patients with a modified anatomical target. Cephalalgia 2011;31(16):1634-41.

136. Peres MF, Sanchez del Rio M, Seabra ML, Tufik S, Abucham J, Cipolla-Neto J, et al. Hypothalamic involvement in chronic migraine. J Neurol Neurosurg Psychiatry 2001;71(6):747-51.

137. Settle M. The hypothalamus. Neonatal Netw: NN 2000;19(6):9-14.

138. Hosoya Y, Matsushita M, Sugiura Y. A direct hypothalamic projection to the superior salivatory nucleus neurons in the rat. A study using anterograde autoradiographic and retrograde HRP methods. Brain Res 1983;266(2):329-33.

139. Wang W, Yu Y, Xu TL. Modulation of acid-sensing ion channels by $\mathrm{Cu}(2+)$ in cultured hypothalamic neurons of the rat. Neuroscience 2007;145(2):631-41.

140. Chen CH, Hsu YT, Chen CC, Huang RC. Acid-sensing ion channels in neurones of the rat suprachiasmatic nucleus. J Physiol 2009;587(Pt 8):1727-37.
141. Ohbuchi T, Sato K, Suzuki H, Okada Y, Dayanithi G, Murphy D, et al. Acid-sensing ion channels in rat hypothalamic vasopressin neurons of the supraoptic nucleus. J Physiol 2010;588(Pt 12): 2147-62.

142. Song N, Zhang G, Geng W, Liu Z, Jin W, Li L, et al. Acid sensing ion channel 1 in lateral hypothalamus contributes to breathing control. PLoS One 2012;7(7):e39982.

143. Hoffmann J, Supronsinchai W, Akerman S, Andreou AP, Winrow $\mathrm{CJ}$, Renger J, et al. Evidence for orexinergic mechanisms in migraine. Neurobiol Dis 2015;74:137-43.

144. Holton C, Goadsby PJ, Holland PR. Acid sensing ion channel 3 inhibitors reduce trigeminovascular activation. Cephalalgia 2016;36(1S): 141.

145. Gao M, Long H, Ma W, Liao L, Yang X, Zhou Y, et al. The role of periodontal ASIC3 in orofacial pain induced by experimental tooth movement in rats. Eur J Orthod 2016;38(6):577-83.

146. Burgos-Vega CC, Quigley LD, Avona A, Price T, Dussor G. Dural stimulation in rats causes brain-derived neurotrophic factordependent priming to subthreshold stimuli including a migraine trigger. Pain 2016;157(12):2722-30.

147. Arngrim N, Schytz HW, Britze J, Amin FM, Vestergaard MB, Hougaard A, et al. Migraine induced by hypoxia: an MRI spectroscopy and angiography study. Brain 2016;139(Pt 3):723-37.

148. Amery WK. Brain hypoxia in migraine: pathophysiologic and therapeutic implications. J Cereb Blood Flow Metab 1982;2 Suppl 1:S62-5.

149. Amery WK. Brain hypoxia: the turning-point in the genesis of the migraine attack? Cephalalgia 1982;2(2):83-109.

150. Takano T, Tian GF, Peng W, Lou N, Lovatt D, Hansen AJ, et al. Cortical spreading depression causes and coincides with tissue hypoxia. Nat Neurosci 2007;10(6):754-62.

151. Edden RA, Harris AD, Murphy K, Evans CJ, Saxena N, Hall JE, et al. Edited MRS is sensitive to changes in lactate concentration during inspiratory hypoxia. J Magn Reson Imaging: JMRI 2010;32(2):320-5

152. Watanabe H, Kuwabara T, Ohkubo M, Tsuji S, Yuasa T. Elevation of cerebral lactate detected by localized $1 \mathrm{H}$-magnetic resonance spectroscopy in migraine during the interictal period. Neurology 1996;47(4):1093-5.

153. Sandor PS, Dydak U, Schoenen J, Kollias SS, Hess K, Boesiger P, et al. MR-spectroscopic imaging during visual stimulation in subgroups of migraine with aura. Cephalalgia 2005;25(7):507-18.

154. Reyngoudt H, De Deene Y, Descamps B, Paemeleire K, Achten E. (1)H-MRS of brain metabolites in migraine without aura: absolute quantification using the phantom replacement technique. Magma (New York, NY). 2010;23(4):227-41.

155. Reyngoudt H, Paemeleire K, Dierickx A, Descamps B, Vandemaele P, De Deene Y, et al. Does visual cortex lactate increase following photic stimulation in migraine without aura patients? A functional (1)H-MRS study. J Headache Pain 2011;12(3):295-302.

156. Hougaard A, Amin FM, Christensen CE, Younis S, Wolfram F, Cramer SP, et al. Increased brainstem perfusion, but no bloodbrain barrier disruption, during attacks of migraine with aura. Brain J Neurol 2017;140(6):1633-42.

157. Schankin CJ, Maniyar FH, Seo Y, Kori S, Eller M, Chou DE, et al. Ictal lack of binding to brain parenchyma suggests integrity of the blood-brain barrier for 11C-dihydroergotamine during glyceryl trinitrate-induced migraine. Brain 2016;139(Pt 7):1994-2001.

158. Baron A, Lingueglia E. Pharmacology of acid-sensing ion channelsphysiological and therapeutical perspectives. Neuropharmacology 2015;94:19-35.

159. Cristofori-Armstrong B, Rash LD. Acid-sensing ion channel (ASIC) structure and function: insights from spider, snake and sea anemone venoms. Neuropharmacology. 2017. 
160. Waldmann R, Voilley N, Mattei MG, Lazdunski M. The human degenerin MDEG, an amiloride-sensitive neuronal cation channel, is localized on chromosome $17 \mathrm{q} 11.2-17 \mathrm{q} 12$ close to the microsatellite D17S798. Genomics 1996;37(2):269-70.

161. Adams CM, Snyder PM, Welsh MJ. Paradoxical stimulation of a DEG/ENaC channel by amiloride. J Biol Chem 1999;274(22): 15500-4.

162. Li WG, Yu Y, Zhang ZD, Cao H, Xu TL. ASIC3 channels integrate agmatine and multiple inflammatory signals through the nonproton ligand sensing domain. Mol Pain 2010;6:88.

163. Dube GR, Lehto SG, Breese NM, Baker SJ, Wang X, Matulenko MA, et al. Electrophysiological and in vivo characterization of A-317567, a novel blocker of acid sensing ion channels. Pain 2005;117(1-2):88-96.

164. Kuduk SD, Di Marco CN, Bodmer-Narkevitch V, Cook SP, Cato MJ, Jovanovska A, et al. Synthesis, structure-activity relationship, and pharmacological profile of analogs of the ASIC-3 inhibitor A-317567. ACS Chem Neurosci 2010;1(1):19-24.

165. Voilley N. Acid-sensing ion channels (ASICs): new targets for the analgesic effects of non-steroid anti-inflammatory drugs (NSAIDs). Curr Drug Targets Inflamm Allergy 2004;3(1):71-9.

166. Dorofeeva NA, Barygin OI, Staruschenko A, Bolshakov KV, Magazanik LG. Mechanisms of non-steroid anti-inflammatory drugs action on ASICs expressed in hippocampal interneurons. J Neurochem 2008;106(1):429-41.

167. Leng T, Lin J, Cottrell JE, Xiong ZG. Subunit and frequencydependent inhibition of acid sensing ion channels by local anesthetic tetracaine. Mol Pain 2013;9:27.

168. Lin J, Chu X, Maysami S, Li M, Si H, Cottrell JE, et al. Inhibition of acid sensing ion channel currents by lidocaine in cultured mouse cortical neurons. Anesth Analg 2011;112(4):977-81.

169. Lei Z, Li X, Wang G, Fei J, Meng T, Zhang X, et al. Inhibition of acid-sensing ion channel currents by propofol in rat dorsal root ganglion neurons. Clin Exp Pharmacol Physiol 2014;41(4):295300 .

170. Tikhonova TB, Nagaeva EI, Barygin OI, Potapieva NN, Bolshakov KV, Tikhonov DB. Monoamine NMDA receptor channel blockers inhibit and potentiate native and recombinant proton-gated ion channels. Neuropharmacology 2015;89:1-10.

171. Lee JYP, Saez NJ, Cristofori-Armstrong B, Anangi R, King GF, Smith MT, et al. Inhibition of acid-sensing ion channels by diminazene and APETx2 evoke partial and highly variable antihyperalgesia in a rat model of inflammatory pain. Br $\mathrm{J}$ Pharmacol 2017.

172. Edvinsson L, Warfvinge K. CGRP receptor antagonism and migraine therapy. Curr Protein Pept Sci 2013;14(5):386-92. 